\title{
Utility of untimed single urine protein/ creatinine ratio as a substitute for $24-h$ proteinuria for assessment of proteinuria in systemic lupus erythematosus
}

Jorge Medina-Rosas ${ }^{1}$, Dafna D. Gladman ${ }^{2,3}$, Jiandong Su${ }^{4}$, Arthy Sabapathy ${ }^{4}$, Murray B. Urowitz ${ }^{2,3}$ and Zahi Touma ${ }^{4^{*}}$

\begin{abstract}
Introduction: In this study, we determined: (1) the utility of an untimed sample of urine protein/creatinine ratio $(P C R)$ as a screening test for proteinuria, (2) its ability to accurately measure proteinuria, and (3) cutoff values for PCR predicting protein content in a 24-h urine collection sample (24hP) of $0.5,1.0$, and $2.0 \mathrm{~g} /$ day.

Methods: Analysis was performed on data from a single lupus cohort (2008-2014). Proteinuria was measured in a $24 \mathrm{hP}$ and with PCR. On the basis of 24hP, samples were divided into 4 groups: group 1, <0.5 g/day; group 2, 0.5$0.99 \mathrm{~g} /$ day; group 3, 1-1.99 g/day; and group 4, $\geq 2 \mathrm{~g} /$ day. To determine the validity of PCR in screening for proteinuria, the Pearson correlation coefficient was determined for the urine samples with normal PCR $(<0.05 \mathrm{~g} /$ $\mathrm{mmol}$ ) and normal $24 \mathrm{hP}(<0.5 \mathrm{~g} /$ day). The sensitivity, specificity, positive predictive value (PPV), and negative predictive value (NPV) of PCR were calculated. To determine the ability of PCR to accurately measure the level of proteinuria, in addition to the correlation between $24 \mathrm{hP}$ and $\mathrm{PCR}$, agreement was determined by intraclass correlation coefficient, concordance correlation coefficient, and Bland-Altman plot between 24hP/24hC and PCR. The best cutoffs for PCR predicting a $24 \mathrm{hP}$ of $0.5,1.0$, and $2.0 \mathrm{~g} /$ day were determined with the receiver operating characteristic curve.
\end{abstract}

Results: The correlation of the samples with normal PCR as well as $24 \mathrm{hP}(n=552)$ was $0.29(p<0.0001)$. PCR sensitivity and specificity against $24 \mathrm{hP}$ were $91 \%$ and $83 \%$, respectively. The PPV was $82.5 \%$, and the NPV was $91.4 \%$. The correlation for all samples $(n=1233)$ was high, but low to moderate for groups $1,2,3$, and 4 . The agreement for all samples was appropriate but poor for groups 1, 2, 3, and 4. PCR cutoffs for 24hP of 0.5, 1.0, and $2.0 \mathrm{~g} /$ day were $0.08,0.16$, and $0.35 \mathrm{~g} / \mathrm{mmol}$, respectively.

Conclusions: PCR can be used as a screening test for proteinuria, and the best cutoff value to predict a 24hP of $0.5 \mathrm{~g} /$ day is $0.08 \mathrm{~g} / \mathrm{mmol}(800 \mathrm{mg} / \mathrm{g})$. The accurate level of proteinuria should be measured by the gold standard test, 24hP.

Keywords: Systematic lupus erythematosus, Lupus nephritis, Kidney

\footnotetext{
*Correspondence: zahi.touma@uhn.ca

${ }^{4}$ University of Toronto Lupus Clinic, Toronto Western Hospital, Centre for Prognosis Studies on the Rheumatic Diseases, Toronto, ON, Canada Full list of author information is available at the end of the article
} 


\section{Introduction}

Lupus nephritis (LN) is an immune complex glomerulonephritis with a cumulative incidence of $54 \%$ [1]. LN can occur early (50\%) as well as years after the diagnosis of systemic lupus erythematosus (SLE) is made (45\%) [2]. The manifestations of renal involvement can be diverse, including proteinuria and active urinary sediment $[3,4]$. Proteinuria is the most common manifestation of LN, being reported in almost $100 \%$ of patients with LN, followed by granular casts, cellular casts, hematuria, and reduced renal function $[1,5]$. Proteinuria is the principal urinary biomarker for the screening of $\mathrm{LN}[5,6]$ and for monitoring disease progression [7-9]. Among the methods for quantification of the proteinuria, the protein content in a 24-h urine collection sample (24hP) has been considered the "gold standard," but this test is cumbersome for patients and sometimes is collected incorrectly [10]. Ginsberg et al. proposed using the untimed sample of urine protein/creatinine ratio (PCR) instead of the 24hP [11]. Several authors have shown a good correlation between PCR and 24hP in diabetes [12], LN [13, 14], and chronic kidney disease [15]. The American College of Rheumatology (ACR) recommends the PCR for use in clinical trials of LN [16], and the European League Against Rheumatism recommendations for the management of adult and pediatric LN suggest using the first morning PCR as a valid measure of proteinuria [17]. Nevertheless, other studies have shown a weak agreement between PCR and 24hP results [18-20]. Clearly, there is no agreement between the existing studies on the utility of PCR. The variance of the results of the published studies is partly related to the method of collection of PCR and the use of inappropriate statistical analyses in various studies. The aim of this study was to determine (1) the utility of the spot urine protein/creatinine ratio as a screening test for proteinuria in patients with SLE, (2) the ability of PCR to accurately measure the level of proteinuria, and (3) the cutoff values for PCR predicting $24 \mathrm{hP}$ of $0.5,1.0$, and $2.0 \mathrm{~g} /$ day.

\section{Methods}

Subjects and assessment

\section{Patient selection}

All adult ( $\geq 18$ years old) patients with lupus at the University of Toronto Lupus Clinic at the Toronto Western Hospital who fulfilled at least four of the ACR revised criteria for the classification of SLE [21] or who met three criteria and had a typical biopsy lesion of SLE were studied.

\section{Inclusion criteria}

All patients' results available in the data collected from May 2008 until December 2014 were screened for inclusion in this study. Patient visits with proteinuria assessment documented by PCR and 24hP, with both tests being done within 4 days, were identified and analyzed.

\section{Exclusion criteria}

We excluded (1) patients with estimated glomerular filtration rate (GFR) or creatinine clearance (calculated from the 24-h urine collection) $<15 \mathrm{ml} / \mathrm{min}$, (2) patients on dialysis, (3) patients with proteinuria not related to LN (e.g., diabetes mellitus, chronic sclerosing LN, and others), and (4) patients with kidney transplantation. The majority $(>90 \%)$ of urine specimens were handled and interpreted at one laboratory, and the appropriate measurements of preservation and shipment of the urine samples were applied.

\section{Assessment of patients and measurement of proteinuria}

We conducted a retrospective analysis of data collected prospectively from May 2008 to December 2014. Patients were attending the lupus clinic at 2- to 6-month intervals regardless of the activity of their disease. Patients' assessments include complete history, physical examination, information about drug treatment, and laboratory examinations. For this study, the laboratory results including GFR and serum creatinine were analyzed. The PCR samples were taken the day of the follow-up visit in the clinic (between 9:00 AM and 5:00 PM), and the results were reviewed. If PCR was abnormal $(>0.05 \mathrm{~g} / \mathrm{mmol})$, patients are contacted and instructed to collect a 24-h urine sample starting the next day. The 24-h urine sample and PCR were also collected at follow-up visits for all patients with proteinuria to check on the response to therapy. The 24-h urine samples were collected as follows: Patients were instructed to empty the bladder in the morning and discard the urine, and from that point onward for $24 \mathrm{~h}$, all urine was to be saved in the container. At the end of that 24-h period, the bladder was emptied, and that urine was saved.

The collection, storage, and use of the clinical and laboratory data on the patients at the center were conducted in accordance with the Declaration of Helsinki and were approved by the Research Ethics Board of the University Health Network, Toronto, ON, Canada. All patients signed an informed consent form before participation.

\section{Adequacy of urine collection}

The adequacy of the 24-h urine sample was assessed by comparing the creatinine from the 24-h urine sample collection $(24 \mathrm{hC})$ with the expected creatinine content $(\mathrm{ExC})$ using the following the formula: $\mathrm{ExC}=28-(0.2 \times$ age $) \times$ weight $(\mathrm{kg})$ in men and $23.8-(0.17 \times$ age $) \times$ weight in women [22]. A stratification for ExC by ethnicity was performed because it is likely that the amount of $\mathrm{ExC}$ varies by ethnicity in addition to body weight and/or muscle mass. Undercollection was defined as a ratio of $(\mathrm{ExC}-24 \mathrm{hC}) /$ ExC $>0.2$, and those samples were excluded [20, 23]. GFR was calculated using the Chronic Kidney Disease Epidemiology Collaboration equation [24]. Patients were 
also screened to ensure they were not taking any drugs that would affect the creatinine clearance, such as trimethoprim.

\section{Definitions of outcome measures}

Proteinuria was defined as $\geq 0.5 \mathrm{~g} / 24$ day, based on the definitions of the Systemic Lupus Erythematosus Disease Activity Index 2000 (SLEDAI-2K) [25] and the ACR criteria [21]. In the database, proteinuria is recorded as related or unrelated to LN activity. If proteinuria is not attributed to SLE activity, it is not scored as present and does not contribute toward the renal component of SLEDAI-2K. The urinalysis interpretation is based on a physician's judgment and interpretation of available laboratory and pathologic results of other tests (biopsy, urine culture). The laboratories consider an abnormal PCR to be $\geq 0.05 \mathrm{~g} / \mathrm{mmol}$.

\section{Statistical analysis}

The sample size was estimated using normal approximation [26] and exact methods [27] for design accuracy in diagnostic tests. The sample size in this study $(\mathrm{n}=1233)$ is beyond the minimum needed to detect an expected sensitivity (Sn) of 0.90 and using a minimal accepted Sn of 0.85 ( $\mathrm{n}=400$ by exact method). Patients' baseline characteristics at the first pair of $24 \mathrm{hP}$ and PCR measurements [mean \pm standard deviation (SD)] and count (\%) were used for continuous and categorical variables, respectively.

Samples were divided into four groups according to protein excretion over $24 \mathrm{~h}$ : group 1, >0.5 g/day; group 2, 0.5-0.99 g/day; group 3, 1-1.99 g/day; and group $4, \geq 2 \mathrm{~g} /$ day.

\section{Validity of $P C R$ in screening for proteinuria}

The Pearson correlation coefficient was determined for the urine samples with normal PCR $(<0.05 \mathrm{~g} / \mathrm{mmol})$ and normal $24 \mathrm{hP}(<0.5 \mathrm{~g} /$ day). The $\mathrm{Sn}$, specificity (Sp), positive predictive value (PPV), negative predictive value (NPV), and positive likelihood ratio (LR+) of PCR were calculated, and in this analysis $24 \mathrm{hP}$ was considered the external construct. The cutoff for PCR was $\geq 0.05 \mathrm{~g} / \mathrm{mmol}$, and the cutoff for $24 \mathrm{hP}$ was $\geq 0.5 \mathrm{~g} /$ day.

\section{Correlation}

The Pearson correlation coefficient was determined for PCR and 24hP for all urine samples overall and for the four groups. Correlations were interpreted as follows [28]: $0.00-0.29=$ negligible, $0.3-0.49=$ low, $0.5-0.7=$ moderate, $0.7-0.9=$ high, and $0.9-0.99=$ very high .

\section{Agreement}

The magnitude of the scales $24 \mathrm{hP}$ (g/day) and PCR $(\mathrm{g} / \mathrm{mmol})$ is different where $24 \mathrm{hP}$ is approximately 7.6 times greater than PCR. Thus, before deriving the agreement between $24 \mathrm{hP}$ and PCR, it was essential to adjust for this difference in both scales. For this purpose, the ratio of $24 \mathrm{hP}$ and $24 \mathrm{hC}$ reported in a $24-\mathrm{h}$ urine sample $(24 \mathrm{hP} /$ $24 \mathrm{hC}$ content) was calculated. In the following analyses, we compared $24 \mathrm{hP} / 24 \mathrm{hC}$ and PCR.

Intraclass correlation coefficient (ICC) $(2, k)$ [29], concordance correlation coefficient (CCC) [30], and the Bland-Altman plot [31] for PCR and $24 \mathrm{hP} / 24 \mathrm{hC}$ were determined. ICC describes the associations and agreement among units in the same group [32]. For the ICC $(2, k)$ the first number, 2 , designates the model, and $k$ signifies the mean of several measurements as the unit of analysis $[29,33]$. The results of the ICC $(2, k)$ were derived after applying square root transformation of the data. $\operatorname{ICC}(2,1)$ was determined in the stratification analysis by ethnicity. The second number, 1 [ICC $(2,1)]$, signifies that $\operatorname{ICC}$ is calculated using a single measurement 1 . ICC $\geq 0.85$ reflects good agreement [34]. The CCC measures the degree to which paired samples fall in the 45-degree line through the origin, being of interest for equivalence of new laboratory methods with the gold standard [30, 35]. CCC $<0.9$ was considered poor [35]. The Bland-Altman plot provides a visual approach to the data whereby the mean and the difference of $\mathrm{PCR}$ and $24 \mathrm{hP} / 24 \mathrm{hC}$ were represented and the limits of agreement $( \pm 2 \mathrm{SD})$ were plotted.

\section{Determination of the best cutoff values for PCR predicting $24 \mathrm{hP}$ of $0.5,1$, and $2 \mathrm{~g} /$ day}

Two different approaches were used: (1) the best cutoff determined based on a $2 \times 2$ contingency table (with $24 \mathrm{hP}$ considered the gold standard test) and (2) logistic regression analysis. Continuous values of PCR were fed into the model as independent variables, and binary high and low $24 \mathrm{hP}$ cutoffs of $0.5,1.0$, or 2.0 were used as dependent variables. The best cutoffs were determined based on the analysis of the receiver operating characteristic (ROC) curve.

\section{Sensitivity analysis}

We conducted a separate analysis of patients taking and those not taking angiotensin-converting enzyme (ACE) inhibitors and/or angiotensin receptor blockers (ARBs) $p$ values $<0.05$ were defined as statistically significant. The Excel 2010 (Microsoft, Redmond, WA, USA) and SAS 9.3 (SAS Institute, Cary, NC, USA) software programs were used for statistical data analysis.

\section{Results}

Patient characteristics

A total of 1730 laboratory urine samples from 421 patients were identified. Of these, 497 samples were excluded because of undercollection in 24-h urine samples, and 1233 urine samples from 322 patients included in the final analysis. The ExC values stratified by ethnicity were as follows: white $17.3 \pm 2.8 \mathrm{mmol} /$ day, black $17.5 \pm 2.2 \mathrm{mmol} /$ day, 
Asian $17.6 \pm 2.6 \mathrm{mmol} /$ day, and other $17.5 \pm 2.6 \mathrm{mmol} /$ day. The patients' demographics are presented in Table 1. The majority of the patients were women $(83.5 \%)$ with lupus disease duration of $11.76 \pm 9.71$ years and age at first $24 \mathrm{hP}$ of $40.26 \pm 14.76$ years. The number of patients in groups 1 , 2 , 3, and 4 were 208, 42, 29, and 43, respectively. Eight patients $(2.5 \%)$ were treated with cyclosporine, three $(1.4 \%)$ in group 1 , one $(2.4 \%)$ in group 2 , one $(3.4 \%)$ in group 3 , and three $(7 \%)$ in the group 4 . No patients were treated with tacrolimus.

\section{Validity of PCR in screening for proteinuria}

Of the 1233 urine samples, 552 samples had normal PCR and 24hP. The Pearson correlation coefficient was $0.29(p<0.0001)$. PCR Sn and Sp against $24 \mathrm{hP}$ were $91 \%$ and $83 \%$, respectively. PPV was $82.5 \%$, NPV was 91.4, and LR+ was 5.4.

\section{Correlation between PCR and 24hP}

For all samples $(\mathrm{n}=1233)$, the correlation was high $(r=$ 0.79) (Fig. 1). However, the correlation was low for group $1(r=0.4)$, negligible for group $2(r=0.2)$, low for group $3(r=0.3)$, and moderate for group 4 was $(r=0.6)$ (all $p<0.05$ ) (Table 2). The correlations of both tests stratified by ethnicity were high for all ethnic groups (white 0.76, black 0.86, Asian 0.78, other ethnicities 0.88; all $p<0.0001$ ).

\section{Agreement between PCR and $24 \mathrm{hP} / 24 \mathrm{hC}$ Intraclass correlation coefficients $(2, k)$}

For all urine samples, ICC was 0.87 ; for group 1 , ICC was 0.52 ; for group 2, ICC was 0.57; for group 3, ICC was 0.73 ; and for group 4, ICC was 0.77 . The agreement was appropriate for all the urine samples; however, it was poor $(<0.85)$ for groups $1,2,3$, and 4 (Table 2$)$, indicating less than appropriate agreement of paired urine samples in the same group and poor reproducibility of the measures for each group.

\section{Concordance correlation coefficients}

For all urine samples, CCC was 0.85 ; for groups $1,2,3$ and 4 , CCCs were $0.62,0.34,0.55$, and 0.44 , respectively. The agreement was poor $(<0.9)$ for all urine samples and for groups 1, 2, 3, and 4 (Table 2), indicating that the PCR levels were not equivalent to the corresponding $24 \mathrm{hP}$ levels in the same patient. The CCC results stratified by ethnicity were as follows: white 0.69 (95\% CI 0.65-0.74), black 0.94 (95\% CI 0.92-0.96), Asian 0.73 (95\% CI 0.63-0.82), and other ethnicities 0.69 (95\% CI 0.60-0.77).

\section{Bland-Altman plot}

The Bland-Altman plot showed that all the paired urine samples from group 1 were between the limits of agreement; however, with increases in $24 \mathrm{hP}$ values, a large difference between the two methods was found that was more obvious in groups 3 and 4 than in the other groups. In group 4, PCR tended to overestimate the $24 \mathrm{hP}$ results. On the Bland-Altman plot, the dots corresponding to groups 3 and 4 are outside 2 SD, signifying poor agreement (Fig. 2).

\section{Cutoff of PCR predicting a 24hP of $0.5,1$ and $2 \mathrm{~g} /$ day}

The contingency table, using $24 \mathrm{hP}$ of $0.5 \mathrm{~g} /$ day as the gold standard and PCR of $0.05 \mathrm{~g} / \mathrm{mmol}$ as the index test, showed Sn and Sp values of $91 \%$ and $83 \%$, respectively. The results of the ROC curve derived from the logistic regression showed that a PCR of $0.08 \mathrm{~g} / \mathrm{mmol}(800 \mathrm{mg} / \mathrm{g})$ reflected $24 \mathrm{hP}$ of $0.5 \mathrm{~g} /$ day, with Sn of $91 \%$ and Sp of $80 \%$ (Table 3). The overall area under the curve was 0.92 (Fig. 3). For the $24 \mathrm{hP}$ cutoffs of 1.0 and $2.0 \mathrm{~g} /$ day, the analyses showed PCR values of $0.16 \mathrm{~g} / \mathrm{mmol}(1600 \mathrm{mg} / \mathrm{g}$; $\mathrm{Sn}$

Table 1 Demographic characteristics of the patients included in the study

\begin{tabular}{|c|c|c|c|c|c|}
\hline Characteristics & $24 \mathrm{hP}<0.5 \mathrm{~g} /$ day & $24 \mathrm{hP} 0.5-0.99 \mathrm{~g} / \mathrm{day}$ & 24hP 1-1.99 g/day & $24 \mathrm{hP} \geq 2.0 \mathrm{~g} /$ day & Total \\
\hline Number of samples (\%) & $662(53.7 \%)$ & $266(21.6 \%)$ & $171(13.9 \%)$ & $174(14.1 \%)$ & $1233(100 \%)$ \\
\hline Number of patients (\%) & $208(64.6 \%)$ & $42(13.0 \%)$ & $29(9 \%)$ & $43(13.3 \%)$ & $322(100 \%)$ \\
\hline Females, n (\%) & $177(85.1 \%)$ & $32(76.2 \%)$ & $23(79.3 \%)$ & 37 (86.0 \%) & $269(83.5 \%)$ \\
\hline Males, n (\%) & $31(14.9 \%)$ & $10(23.8 \%)$ & $6(20.7 \%)$ & $6(14.0 \%)$ & $53(16.5 \%)$ \\
\hline Whites, n (\%) & $118(56.7 \%)$ & $23(54.8 \%)$ & $11(37.9 \%)$ & $21(48.8 \%)$ & $173(53.7 \%)$ \\
\hline Blacks, n (\%) & $37(17.8 \%)$ & $7(16.7 \%)$ & $6(20.7 \%)$ & $12(27.9 \%)$ & $62(19.3 \%)$ \\
\hline Asians, n (\%) & $21(10.1 \%)$ & $6(14.3 \%)$ & $5(17.2 \%)$ & $4(9.3 \%)$ & $36(11.2 \%)$ \\
\hline Other ethnicities, n (\%) & $32(15.4 \%)$ & $6(14.3 \%)$ & 7 (24.1\%) & $6(14.0 \%)$ & $51(15.8 \%)$ \\
\hline Disease duration, yr (SD) & $13.02 \pm 10.38$ & $8.90 \pm 6.23$ & $11.54 \pm 9.49$ & $8.61 \pm 8.07$ & $11.76 \pm 9.71$ \\
\hline Age at first $24 \mathrm{hP}, \mathrm{yr}(\mathrm{SD})$ & $42.26 \pm 14.88$ & $37.02 \pm 16.14$ & $38.33 \pm 13.66$ & $35.05 \pm 11.58$ & $40.26 \pm 14.76$ \\
\hline Serum creatinine, $\mu \mathrm{mol} / \mathrm{L}$ (SD) & $84.39 \pm 47.30$ & $87.76 \pm 42.56$ & $87.76 \pm 42.56$ & $80.49 \pm 58.02$ & $84.18 \pm 47.03$ \\
\hline Patients taking prednisone, n (\%) & $79(62.7 \%)$ & $22(59.5 \%)$ & $16(59.3 \%)$ & $31(77.5 \%)$ & $148(64.3 \%)$ \\
\hline Patients taking immunosuppressives, n (\%) & $70(55.6 \%)$ & $25(67.6 \%)$ & $14(51.9 \%)$ & $28(70.0 \%)$ & $137(59.6 \%)$ \\
\hline
\end{tabular}

$24 \mathrm{hP}$ Protein content in a 24-h urine collection sample 


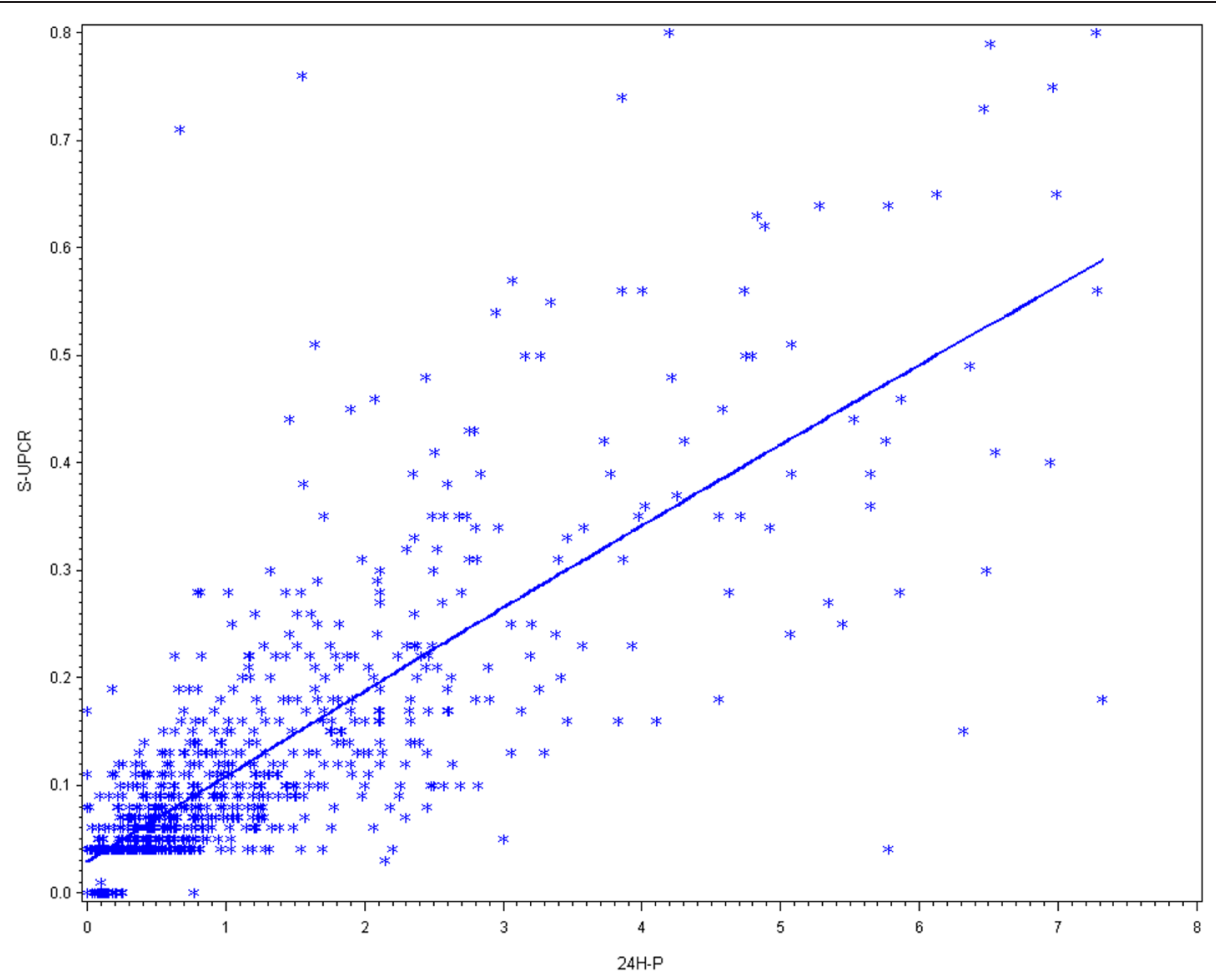

Fig. 1 Scatterplot of correlation between protein content in a 24-h urine collection sample; (24hP) and untimed sample of urine protein/creatinine ratio for all urine samples. $P C R$ spot urine protein/creatinine ratio

$90 \%$ and Sp $83 \%)$ and $0.35 \mathrm{~g} / \mathrm{mmol}(3500 \mathrm{mg} / \mathrm{g}$; Sn $91 \%$ and Sp $85 \%)$, respectively.

\section{Sensitivity analyses for ACE inhibitors and/or ARB}

The results for patients taking ACE inhibitors and/or ARB showed that, correlation among the 164 patients taking ACE inhibitors and/or ARB, 624 paired samples were identified. Although the correlation between 24hP and PCR for all samples was 0.77 , in group 1 $(\mathrm{n}=288)$ it was 0.4 ; in group $2(\mathrm{n}=129)$, it was 0.2 ; in group $3(n=114)$, it was 0.3 ; and in group $4(n=95)$, it was 0.6 .

Table 2 Results of correlations between 24hP and PCR and agreement between 24hP/24hC and PCR

\begin{tabular}{|c|c|c|c|c|c|c|}
\hline & Correlation & Interpretation ${ }^{a}$ & $\operatorname{ICC}(2, k)$ & Interpretation ${ }^{b}$ & $\mathrm{CCC}$ & Interpretation \\
\hline & $p$ value & & $95 \% \mathrm{Cl}$ & & $95 \% \mathrm{Cl}$ & \\
\hline \multirow[t]{2}{*}{ All samples } & 0.79 & High & 0.87 & Appropriate & 0.85 & Poor \\
\hline & $<0.0001$ & & $0.83-0.91$ & & $0.83-0.87$ & \\
\hline $24 \mathrm{hP}$ & 0.4 & Low & 0.52 & Poor & 0.62 & Poor \\
\hline$<0.5$ g/day & $<0.0001$ & & $0.50-0.53$ & & $0.56-0.67$ & \\
\hline $24 \mathrm{hP}$ & 0.2 & Negligible & 0.57 & Poor & 0.34 & Poor \\
\hline $0.5-0.99 \mathrm{~g} /$ day & 0.0007 & & $0.55-0.58$ & & $0.24-0.46$ & \\
\hline $24 \mathrm{hP}$ & 0.3 & Low & 0.73 & Poor & 0.55 & Poor \\
\hline 1-1.99 g/day & 0.001 & & $0.70-0.76$ & & $0.43-0.68$ & \\
\hline $24 \mathrm{hP}$ & 0.6 & Moderate & 0.77 & Poor & 0.44 & Poor \\
\hline$\geq 2.0 \mathrm{~g} / \mathrm{day}$ & 0.0001 & & $0.70-0.83$ & & $0.35-0.53$ & \\
\hline
\end{tabular}

CCC concordance correlation coefficient, $\mathrm{Cl}$ confidence interval, $24 \mathrm{hC}$ measured creatinine content in a 24 -h urine sample collection, $24 \mathrm{hP}$ protein content in a 24 -h urine collection sample, ICC intraclass correlation coefficient

The ratio of the protein content and the creatinine content in a 24 -h urine collection sample $(24 \mathrm{hP} / 24 \mathrm{hC}$ ) was calculated by dividing $24 \mathrm{hP}$ ( $\mathrm{g} / \mathrm{day}) \mathrm{by}$ creatinine content (mmol/day) reported in the results of the same $24 \mathrm{~h}$ urine sample

${ }^{a}$ Correlation: negligible $(r=0.00-0.29)$, low $(r=0.3-0.49)$, moderate $(r=0.5-0.7)$, high $(r=0.7-0.9)$, very high $(r=0.9-0.99)$

${ }^{\mathrm{b}}$ Measure of agreement: ICC $(2, k) \geq 0.85=$ good reliability (agreement)

${ }^{\mathrm{c}}$ Measure of agreement: $\mathrm{CCC}<0.9=$ poor agreement 


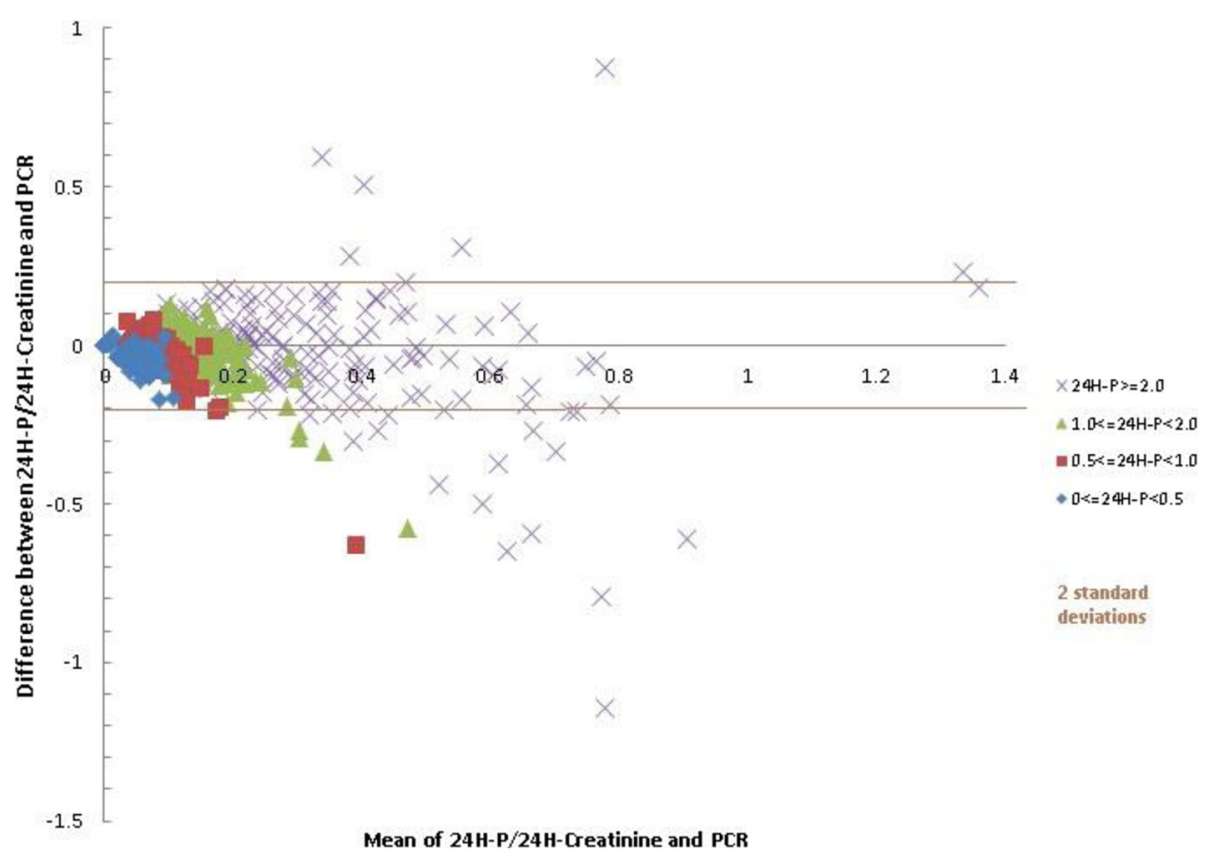

Fig. 2 Bland-Altman plot for ratios of protein content and creatinine content in 24-h urine collection samples (24H-P/24-H Creatinine) and untimed samples of urine protein/creatinine ratio (PCR)

For all urine samples, ICC was 0.91 ; for groups $1,2,3$, and 4 , ICCs were $0.48,0.60,0.64$, and 0.84 , respectively. For all samples, CCC was 0.93 ; for groups $1,2,3$, and 4 , CCCs were $0.59,0.25,0.56$, and 0.85 , respectively.

For the $24 \mathrm{hP}$ cutoffs of $0.5,1.0$, and $2.0 \mathrm{~g} /$ day, the analyses showed PCR values of $0.07 \mathrm{~g} / \mathrm{mmol}(700 \mathrm{mg} / \mathrm{g}$; $\mathrm{Sn}$ $91 \%$ and $\mathrm{Sp} 82 \%), 0.11 \mathrm{~g} / \mathrm{mmol}(1100 \mathrm{mg} / \mathrm{g}$; Sn $90 \%$ and Sp $73 \%$ ), and $0.15 \mathrm{~g} / \mathrm{mmol}(1500 \mathrm{mg} / \mathrm{g} ; \mathrm{Sn} 90 \%$ and Sp $79 \%)$, respectively.

The analysis for patients not taking ACE inhibitors and/ or ARBs showed results similar to those for the patients taking ACE inhibitors and/or ARBs. CCC was 0.54 for all urine samples overall; for groups 1, 2, 3, and 4, CCCs were $0.54,0.36,0.39$, and 0.36 , respectively.

\section{Discussion}

In daily practice, proteinuria in patients with SLE has great importance for the diagnosis of LN, monitoring of disease activity, and prognosis $[6,8]$. Thus, it is very important to use the most accurate method for measurement of proteinuria. 24hP is the gold standard for proteinuria assessment in LN, but PCR has become a widely accepted method of measurement of proteinuria in clinical practice, research settings, and clinical trials $[9,36]$.

The expected creatinine content for different ethnic groups was similar in our patients, without abnormal results for any group. Besides this, whereas the correlation overall of all the paired urine samples and for the ethnic groups was high, it decreased for the individual groups,

Table 3 ROC classification for best PCR cutoffs reflecting 24hP $0.5 \mathrm{~g} /$ day using binary 24hP as the gold standard

\begin{tabular}{|c|c|c|c|c|c|c|c|}
\hline Probability level & $\begin{array}{l}\text { Number of correctly } \\
\text { predicted events }\end{array}$ & $\begin{array}{l}\text { Number of correctly } \\
\text { predicted nonevents }\end{array}$ & $\begin{array}{l}\text { Number of nonevents } \\
\text { predicted as events }\end{array}$ & $\begin{array}{l}\text { Number of events } \\
\text { predicted as nonevents }\end{array}$ & Sensitivity & Specificity & $P C R$ \\
\hline 0.983 & 65 & 570 & 1 & 597 & 0.098 & 0.998 & 0.138 \\
\hline 0.970 & 66 & 570 & 1 & 596 & 0.100 & 0.998 & 0.128 \\
\hline 0.909 & 66 & 569 & 2 & 596 & 0.100 & 0.996 & 0.108 \\
\hline 0.847 & 552 & 519 & 52 & 110 & 0.834 & 0.909 & 0.098 \\
\hline 0.754 & 579 & 493 & 78 & 83 & 0.875 & 0.863 & 0.088 \\
\hline 0.628 & 604 & 458 & 113 & 58 & 0.912 & 0.802 & 0.078 \\
\hline 0.340 & 634 & 385 & 186 & 28 & 0.958 & 0.674 & 0.058 \\
\hline
\end{tabular}

$24 \mathrm{hP}$ protein content in a 24-h urine collection sample, $P C R$ untimed sample of urine protein/creatinine ratio, $R O C$ receiver operating characteristic Boldface type indicates statistically significant values 


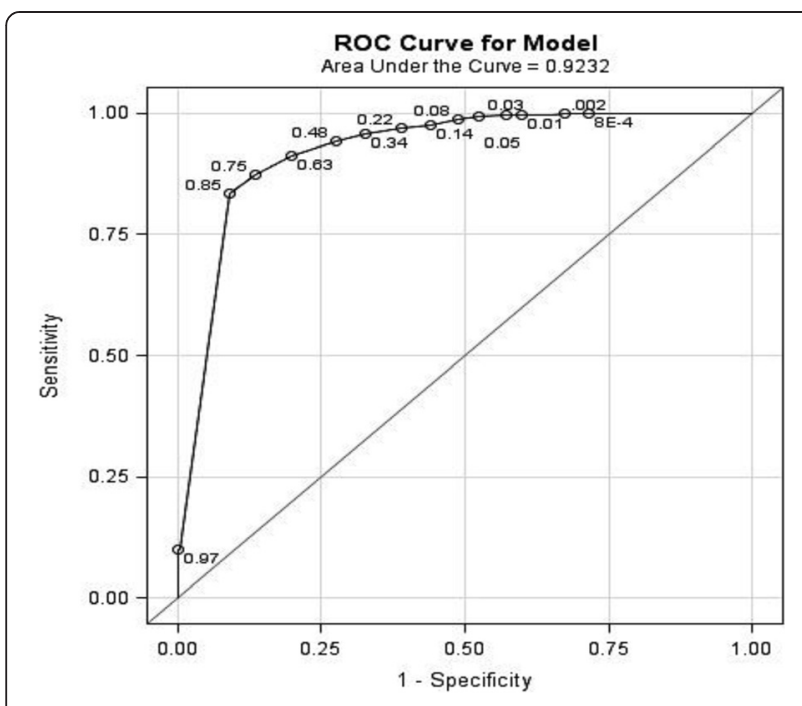

Fig. 3 Receiver operating characteristic (ROC) curve for best cutoff of untimed samples of urine protein/creatinine ratio using binary protein content in a 24-h urine collection sample (24hP) as the gold standard (24hP cutoff $0.5 \mathrm{~g} /$ day)

especially those with higher levels of proteinuria. It is remarkable that the correlation was negligible for the $24 \mathrm{hP}$ 0.5-0.99 g/day group, in which this amount of protein excretion should alert the clinician about kidney involvement in the course of SLE. For the groups with higher levels of proteinuria (24hP $1-1.99$ and $\geq 2.0 \mathrm{~g} /$ day), although the correlations improved, they did not reach a high threshold, making it difficult to confirm that PCR can replace $24 \mathrm{hP}$ for diagnostic purposes. Leung et al. also showed a high correlation for all samples, but correlation dropped with larger levels of proteinuria [20].

Correlation and agreement are two different concepts for a new test. To replace a gold standard test, the new test has to demonstrate agreement with the gold standard. In our study, we used different statistical methods to study agreement. Although the ICC for all the paired urine samples was appropriate, it was poor for the four independent groups. The CCC showed poor agreement for all the samples and in each of the four groups. The Bland-Altman plot confirmed the lack of agreement between PCR and $24 \mathrm{hP}$, in particular for proteinuria $>1 \mathrm{~g} /$ day. These results support the findings of poor diagnostic performance of PCR for the studied 24hP groups and emphasize the limited utility of PCR as a substitute for $24 \mathrm{hP}$.

Salesi et al. found a high correlation between $24 \mathrm{hP}$ and PCR in 74 female patients [37]. Chitalia et al. pointed out that correlation analysis does not enable a reliable decision to be made in order to replace one with the other [38]. Bland and Altman noted that the correlation is described over the entire sample range and may conceal disagreement between two tests at the extreme ranges of the same sample, and it is possible to have a high correlation with prediction intervals that may be unacceptably wide [39]. Birmingham et al. studied 64 patients with SLE and showed a moderate correlation and weak agreement for samples between 0.5 and $3.0 \mathrm{~g} /$ day [18]. Choi et al. studied 102 patients and found poor agreement for the group with 24hP 0.5-3 g/day [13]. Zhang et al. found poor agreement in a study of 90 samples [23]. Conclusions based on correlation alone supported the substitution of $24 \mathrm{hP}$ by PCR, whereas studies with more appropriate statistical analyses involving agreement clearly showed a weak agreement between both tests. Our study, supported by the use of appropriate statistical analyses, emphases the inadequate validity of PCR as a surrogate for $24 \mathrm{hP}$.

We calculated the best cutoff of PCR predicting a $24 \mathrm{hP}$ of $0.5,1$, or $2 \mathrm{~g} /$ day. To decide on the best combination of $\mathrm{Sn}$ and Sp for a screening test, it is important to consider the costs and possible harms associated with the test [40]. The ROC curve showed that PCR of $0.08,0.16$, or $0.35 \mathrm{~g} /$ mmol would reflect $24 \mathrm{hP}$ of $0.5,1$, or $2 \mathrm{~g}$ /day, respectively. Leung et al. [20] determined the PCR cutoffs for $24 \mathrm{hP}$ of $0.5,1$, and $3.5 \mathrm{~g} /$ day in 129 samples from 82 patients, and their results $(0.45,0.7$, and $1.85 \mathrm{mg} / \mathrm{mg}$, respectively) were different from ours. Some of the patients in Leung et al.'s study did not complete the 24-h urine collection, causing the $\mathrm{Sn}$ and Sp to be underestimated. In our study, all the paired samples were available, and our sample size was larger. PCR is a test used for clinical decision-making, but when the quantification of protein is needed, the $24 \mathrm{hP}$ still is the gold standard.

In the present study, the $\mathrm{Sn}$ analyses conducted on patients maintained on ACE inhibitors and/or ARBs, as well as on patients not taking ACE inhibitors and/or ARBs, also showed poor reproducibility of the results for $24 \mathrm{hP}$ by PCR; thus, PCR cannot be substituted for $24 \mathrm{hP}$.

Our study has some limitations. The proteinuria measurement tests (24hP and PCR) were not performed on the same day. However, in this analysis, both tests were performed in less than a 4-day period, which is considered too short to affect the confidence of the proteinuria measurement. Group 4 had a relatively small sample size (43 patients with 174 paired urine samples), thus limiting the generalizability of our findings. However, our sample size was bigger than the samples in other studies with similar findings [18]. We conducted a cross-sectional study, and thus analyses of serial samples are not presented. This is a very relevant question that needs to be answered in future studies and may be more suitable in an incident cohort of patients with lupus.

\section{Conclusions}

Clinicians in daily practice managing SLE and LN rely on the accuracy and validity of laboratory results to make appropriate decisions, such as ordering a kidney biopsy or initiating and/or modifying treatment for $\mathrm{LN}$ based on 
proteinuria level. On the basis of the results of our study, we conclude that PCR can be used as screening test but still lacks the performance level of the gold standard test, $24 \mathrm{hP}$, in measuring proteinuria. The importance of this finding is that clinicians cannot rely on PCR results to make treatment decisions. PCR can be used as a screening test in patients with SLE, but every abnormal result should be confirmed with a 24-h urine collection sample to detect the precise level of proteinuria.

\begin{abstract}
Abbreviations
ACE: Angiotensin-converting enzyme; ACR: American College of Rheumatology; ARB: Angiotensin receptor blocker; CCC: Concordance correlation coefficient; $\mathrm{Cl}$ : Confidence interval; ExC: Expected creatinine content in a 24-h urine sample collection; GFR: Glomerular filtration rate; $24 \mathrm{hC}$ : Measured creatinine content in a 24-h urine sample collection; $24 \mathrm{hP}$ : Protein content in a 24-h urine collection sample; $24 \mathrm{hP} / 24 \mathrm{hC}$ : Ratio of the protein content and the creatinine content in a 24-h urine collection sample; ICC: Intraclass correlation coefficient; LN: Lupus nephritis; LR+: Positive likelihood ratio PCR, Untimed sample of urine protein/ creatinine ratio; ROC: Receiver operating characteristic; SD: Standard deviation; SLE: Systemic lupus erythematosus; SLEDAI-2K: Systemic Lupus Erythematosus Disease Activity Index 2000; SD: Standard deviation; Sn: Sensitivity; Sp: Specificity; PCR: Spot urine protein/creatinine ratio.
\end{abstract}

\section{Competing interests}

The authors declare that they have no competing interests.

\section{Authors' contributions}

JMR collected the data, participated in the design of the study, and drafted and edited the manuscript. DDG conceived of the study and helped to revise and edit the manuscript. JS participated in the design of the study, performed the statistical analysis, and helped to revise and edit the manuscript. AS collected the data and edited the manuscript. MBU conceived of the study and helped to revise and edit the manuscript. ZT conceived of the study, participated in the design of the study, and drafted and edited the manuscript. All authors read and approved the final manuscript.

\section{Author details}

${ }^{1}$ Clinical and Research Fellow, University of Toronto Lupus Clinic, Toronto Western Hospital, Centre for Prognosis Studies in the Rheumatic Diseases, Toronto, ON, Canada. ${ }^{2}$ Toronto Western Research Institute, University of Toronto, Toronto, ON, Canada. ${ }^{3}$ University of Toronto Lupus Clinic, Centre for Prognosis Studies in the Rheumatic Diseases, Toronto Western Hospital, University of Toronto, Toronto, ON, Canada. ${ }^{4}$ University of Toronto Lupus Clinic, Toronto Western Hospital, Centre for Prognosis Studies on the Rheumatic Diseases, Toronto, ON, Canada.

\section{Received: 21 May 2015 Accepted: 29 September 2015}

Published online: 24 October 2015

\section{References}

1. Bastian HM, Roseman JM, McGwin Jr G, Alarcón GS, Friedman AW, Fessler BJ, et al. Systemic lupus erythematosus in three ethnic groups. XII. Risk factors for lupus nephritis after diagnosis. Lupus. 2002;11(3):152-60.

2. Dye-Torrington $D$, Urowitz MB, Ibanez D, Gladman DD. Late versus early development of lupus nephritis [abstract]. Arthritis Rheum. 2011;63 Suppl 10:2284.

3. Sprangers $B$, Monahan M, Appel GB. Diagnosis and treatment of lupus nephritis flares_an update. Nat Rev Nephrol. 2012;8(12):709-17.

4. Touma Z, Gladman DD, Urowitz MB, Beyene J, Uleryk EM, Shah PS. Mycophenolate mofetil for induction treatment of lupus nephritis: a systematic review and metaanalysis. J Rheumatol. 2011;38(1):69-78.

5. Cameron JS. Lupus nephritis. J Am Soc Nephrol. 1999;10(2):413-24.

6. Balow JE. Clinical presentation and monitoring of lupus nephritis. Lupus. 2005;14(1):25-30.

7. Dall'Era M, Cisternas MG, Smilek DE, Straub L, Houssiau FA, Cervera R, et al. Predictors of long-term renal outcome in lupus nephritis trials: lessons learned from the Euro-Lupus Nephritis cohort. Arthritis Rheumatol. 2015;67(5):1305-13.
8. Touma Z, Urowitz MB, Ibañez D, Gladman DD. Time to recovery from proteinuria in patients with lupus nephritis receiving standard treatment. J Rheumatol. 2014;41(4):688-97.

9. Furie R, Nicholls K, Cheng TT, Houssiau F, Burgos-Vargas R, Chen SL, et al. Efficacy and safety of abatacept in lupus nephritis: a twelve-month, randomized, double-blind study. Arthritis Rheumatol. 2014;66(2):379-89.

10. Mitchell SC, Sheldon TA, Shaw AB. Quantification of proteinuria: a reevaluation of the protein/creatinine ratio for elderly subjects. Age Ageing. 1993;22(6):443-9.

11. Ginsberg JM, Chang BS, Matarese RA, Garella S. Use of single voided urine samples to estimate quantitative proteinuria. N Engl J Med. 1983;309(25):1543-6.

12. Rodby RA, Rohde RD, Sharon Z, Pohl MA, Bain RP, Lewis EJ, et al. The urine protein to creatinine ratio as a predictor of 24-hour urine protein excretion in type 1 diabetic patients with nephropathy. Am J Kidney Dis. 1995;26(6):904-9.

13. Choi IA, Park JK, Lee EY, Song YW, Lee EB. Random spot urine protein to creatinine ratio is a reliable measure of proteinuria in lupus nephritis in Koreans. Clin Exp Rheumatol. 2013;31(4):584-8.

14. Chotayaporn T, Kasitanon N, Sukitawut W, Louthrenoo W. Comparison of proteinuria determination by urine dipstick, spot urine protein creatinine index, and urine protein 24 hours in lupus patients. J Clin Rheumatol. 2011;17(3):124-9.

15. Wahbeh AM, Ewais MH, Elsharif ME. Comparison of 24-hour urinary protein and protein-to-creatinine ratio in the assessment of proteinuria. Saudi J Kidney Dis Transpl. 2009;20(3):443-7.

16. Renal Disease Subcommittee of the American College of Rheumatology Ad Hoc Committee on Systemic Lupus Erythematosus Response Criteria. The American College of Rheumatology response criteria for proliferative and membranous renal disease in systemic lupus erythematosus clinical trials. Arthritis Rheum. 2006;54(2):421-32.

17. Bertsias GK, Tektonidou M, Amoura Z, Aringer M, Bajema I, Berden JH, et al. Joint European League Against Rheumatism and European Renal Association-European Dialysis and Transplant Association (EULAR/ERA-EDTA) recommendations for the management of adult and paediatric lupus nephritis. Ann Rheum Dis. 2012;71(11):1771-82.

18. Birmingham DJ, Rovin BH, Shidham G, Nagaraja HN, Zou X, Bissell M, et al. Spot urine protein/creatinine ratios are unreliable estimates of $24 \mathrm{~h}$ proteinuria in most systemic lupus erythematosus nephritis flares. Kidney Int. 2007;72(7):865-70.

19. Birmingham DJ, Shidham G, Perna A, Fine DM, Bissell M, Rodby R, et al. Spot PC ratio estimates of 24-hour proteinuria are more unreliable in lupus nephritis than in other forms of chronic glomerular disease. Ann Rheum Dis 2014;73(2):475-6.

20. Leung YY, Szeto CC, Tam LS, Lam CW, Li EK, Wong KC, et al. Urine proteinto-creatinine ratio in an untimed urine collection is a reliable measure of proteinuria in lupus nephritis. Rheumatology. 2007:46(4):649-52.

21. Hochberg MC. Updating the American College of Rheumatology revised criteria for the classification of systemic lupus erythematosus. Arthritis Rheum. 1997:40(9):1725.

22. Cockcroft DW, Gault MH. Prediction of creatinine clearance from serum creatinine. Nephron. 1976;16(1):31-41.

23. Zhang $Q$, Sun $L$, Jin L. Spot urine protein/creatinine ratio is unreliable estimate of $24 \mathrm{~h}$ proteinuria in lupus nephritis when the histological scores of activity index are higher. Lupus. 2015;24:943-7.

24. Levey AS, Stevens LA, Schmid CH, Zhang YL, Castro 3rd AF, Feldman HI, et al. A new equation to estimate glomerular filtration rate. Ann Intern Med. 2009;150(9):604-12. A published erratum appears in Ann Intern Med. 2011;155(6):408.

25. Gladman DD, Ibañez D, Urowitz MB. Systemic Lupus Erythematosus Disease Activity Index 2000. J Rheumatol. 2002;29(2):288-91.

26. Flahault A, Cadilhac M, Thomas G. Sample size calculation should be performed for design accuracy in diagnostic test studies. J Clin Epidemiol. 2005;58(8):859-62.

27. Chu H, Cole SR. Sample size calculation using exact methods in diagnostic test studies. J Clin Epidemiol. 2007;60(11):1201-2.

28. Mukaka MM. Statistics corner: a guide to appropriate use of correlation coefficient in medical research. Malawi Med J. 2012;24(3):69-71.

29. Shrout PE, Fleiss JL. Intraclass correlations: uses in assessing rater reliability. Psychol Bull. 1979;86(2):420-8.

30. Lin LI. A concordance correlation coefficient to evaluate reproducibility. Biometrics. 1989;45(1):255-68. 
31. Bland JM, Altman DG. Statistical methods for assessing agreement between two methods of clinical measurement. Lancet. 1986;1(8476):307-10.

32. Donner A, Koval JJ. The estimation of intraclass correlation in the analysis of family data. Biometrics. 1980;36(1):19-25.

33. Portney LG, Watkins MP. Statistical measures of reliability. In: Foundations of clinical research: applications to practice. 3rd ed. Upper Saddle River, NJ: Pearson/Prentice Hall; 2008. p. 557-85.

34. Streiner DL, Norman GR. Reliability, generalizability theory and validity. In Health measurement scales: a practical guide to their development and use. 4th ed. New York: Oxford University Press; 2008. p. 167-276.

35. McBride GB. Using statistical methods for water quality management: issues, problems, and solutions. Hoboken, NJ: Wiley-Interscience; 2005.

36. Rovin BH, Furie R, Latinis K, Looney RJ, Fervenza FC, Sanchez-Guerrero J, et al. Efficacy and safety of rituximab in patients with active proliferative lupus nephritis: the Lupus Nephritis Assessment with Rituximab study. Arthritis Rheum. 2012;64(4):1215-26.

37. Salesi M, Karimifar M, Farajzadegan Z, Esalatmanesh K, Khosravi S, Fallahi P, et al. The protein-creatinine ratio in spot morning urine samples and 24-h urinary protein excretion in patients with systemic lupus erythematosus. Rheumatol Int. 2009;29(5):503-7.

38. Chitalia VC, Kothari J, Wells EJ, Livesey JH, Robson RA, Searle M, et al. Costbenefit analysis and prediction of 24-hour proteinuria from the spot urine protein-creatinine ratio. Clin Nephrol. 2001;55(6):436-47.

39. Bland JM, Altman DG. Comparing two methods of clinical measurement: a personal history. Int J Epidemiol. 1995;24 Suppl 1:S7-14

40. Barratt A, Irwig L, Glasziou P, Cumming RG, Raffle A, Hicks N, et al. Users' quides to the medical literature: XVII. How to use guidelines and recommendations about screening. JAMA. 1999;281(21):2029-34.

\section{Submit your next manuscript to BioMed Central and take full advantage of:}

- Convenient online submission

- Thorough peer review

- No space constraints or color figure charges

- Immediate publication on acceptance

- Inclusion in PubMed, CAS, Scopus and Google Scholar

- Research which is freely available for redistribution 